FACTA UNIVERSITATIS

Series: Physical Education and Sport, Vol. 17, No 3, 2019, pp. 437 - 452

https://doi.org/10.22190/FUPES191205039K

Research article

\title{
COMPARATIVE ANALYSIS OF GOLF CLUBHEAD MOTION AT IMPACT
}

UDC 796.352.2

796.012:612.766

\author{
Simon Kraśna ${ }^{1}$, Milan Čoh ${ }^{2}$, Ivan Prebil ${ }^{1}$, Krzysztof Mackala $^{3}$ \\ ${ }^{1}$ Faculty of Mechanical Engineering, University of Ljubljana, Ljubljana, Slovenia \\ ${ }^{2}$ Faculty of Sport, University of Ljubljana, Ljubljana, Slovenia \\ ${ }^{3}$ Faculty of Physical Education, University of School of Physical Education (AWF), \\ Wroclaw, Poland
}

\begin{abstract}
The purpose of the study was to investigate clubhead kinematics during the impact phase of a golf swing. Three highly skilled golfers of a distinguished body type were instructed to perform driver, 6-iron and pitching wedge trials. A high-speed imaging system was used to capture the clubhead motion near the impact. Conventional golf swing parameters were analysed for comparison. Additionally, a circular arc was fitted to the clubhead path, and the moving trihedron was introduced as a reference frame for observing the clubhead rotation. Despite differences in their body type, golfers achieved comparable clubhead speed, while the radius of the fitted circular arc was in a narrow range. The moving trihedron, together with conventional parameters of the golf swing, enabled additional insight to the clubhead motion and clubface orientation. Individual swing characteristics, which result in the clubhead motion prior to impact, could clearly be observed, enabling improvement of the golfer's swing technique.
\end{abstract}

Key words: Golf Swing, Experiment, Motion Analysis, Biomechanics, Moving Trihedron

\section{INTRODUCTION}

The golf swing is known as one of the most complex actions in sport. There are several ways to analyse the golf swing, each with advantages and limitations, depending on the purpose. Experimental results from live golfers inherently include variations in body type, posture, consistency, muscular pattern and skill, which are parameters that

\footnotetext{
Received December 05, 2019/ Accepted December 19, 2019

Corresponding author: Krzysztof Mackala

Faculty of Physical Education, University of School of Physical Education (AWF), al. Ignacego Jana Paderewskiego 35, 51-612 Wroclav, Poland

Phone: + 38713473200600081772 •E-mail: krzysztof.mackala@awf.wroc.pl

(C) 2019 by University of Niš, Serbia | Creative Commons License: CC BY-NC-ND
} 
might be difficult to deal with. Computer simulations on the other hand offer greater flexibility and more focused analysis of individual parameters of the golf swing. Numerous models, simple and more complex ones, were developed for golf swing modelling (Sandhu, Millard \& McPhee, 2010; Penner, 2009; Betzler, Monk \& Wallace, 2008).

Depending on the club used, the golfer's swing should produce optimal impact conditions for maximizing distance of the ball flight, precision, control and consistency over the shots. Although the golf swing is often modelled as a double pendulum, it is essentially a 3D event. The impact conditions between the clubhead and the ball can be assessed with commonly used parameters describing orientation and motion of the clubhead with respect to the ball. The factors influencing the clubhead motion were studied extensively in the literature. Moreover, a lot of data can be obtained from golf launch monitors.

Nesbit (2005) showed that there is no fixed plane of the swing, and there is a $9-12^{\circ}$ angle between the plane traced out by the hands and the clubhead plane. The steepness of the leading hand plane does not affect the impact conditions, while that remained an open question for the steepness of the clubhead swing plane (MacKenzie, 2012).

Based on a flexible shaft model driven from live golfer data, a close connection between the clubhead deflection and the applied torque was observed (McGinnis \& Nesbit, 2010; Nesbit \& McGinnis, 2009). For a skilled golfer, a rapid decrease of the hub path radius and shaft deflection was predicted, which was associated with a large radial force and nearly zero values for tangential force and wrist torque. However, the clubhead motion was constrained to a single swing plane, thus neglecting the toe up/down deflection and the rotation around the shaft axis (McGinnis \& Nesbit, 2010). Yet, due to the shaft characteristic bending mode the clubhead rotation can occur even at small deflections, influencing dynamic loft and face angle. From the lag deflection early in the downswing, the shaft recoils to the lead deflection near the impact (MacKenzie, 2011; MacKenzie \& Sprigings, 2009a; 2009b; $2009 \mathrm{c})$. The radial force acting on the clubhead contributes to the lead and toe down deflection near the impact, which tends to increase dynamic loft and close face angle. Betzler, Monk, Wallace and Otto (2012) showed that the kick-velocity resulting from the recoil can add about $0.8 \%$ to the clubhead speed, while only small changes of dynamic loft and face angle with more flexible shaft were found, compared to the influence of a golfer. The model developed by MacKenzie (2011) was fitted to a golfer of a particular size. The simulated muscle coordination, which resulted from optimizing the model for maximum clubhead speed, might not be suitable for other golfers while the physiological muscle limits should be incorporated (Betzler, Monk, \& Wallace, 2008). To avoid possible unrealistic muscle coordination in modelling, performing measurements on live golfers may represent a better strategy.

Golfers exhibit identical muscle coordination when using different clubs, while differences in the clubhead motion are related to club length and mass properties (Egret, Vincent, \& Weber, 2003). Elite golfers perform the swing with nearly the same timing sequence and power for driver and iron trials, with the optimal muscle activation pattern depending on an individual golfer (Kenny, McCloy, \& Wallace, 2008). Only small absolute variations in the clubhead velocity and carry distance were found with different drivers (Kenny, Wallace, \& Otto, 2008), which supports the individualized approach to golf swing analysis. 
Compared to drivers, there are not many studies published regarding the use of iron clubs. Healy, Moran, and Dickson (2011) focused on body segment motion and sequencing when using 5-irons. They attempted to identify key factors in golfer's kinematics that contribute to longer distance, but did not report parameters of clubhead motion in their study. The upper body, the leading arm and the clubhead do not move in a single consistent plane during the downswing (Coleman \& Rankin, 2005); however, the swing plane is well established at $0.1 \mathrm{~s}$ before the impact (Vaughan, 1981). Coleman and Anderson (2007) compared ten skilled golfers using a driver, 5-iron and pitching wedge in a laboratory environment. The steepest angle of the swing plane, fitted to the club motion over the whole downswing, was estimated from the pitching wedge and the shallowest one from the driver. They established that the swing parameters depend on each golfer and club. Due to a low sampling frequency, $120 \mathrm{~Hz}$, the impact identification was troublesome, as well as analysis of clubhead motion near the impact.

Our study focused on the clubhead motion near the impact. Although there are various aspects regarding the swing plane, body posture, muscle coordination pattern, and shaft deflection, the ultimate goal of the golfer's action is to provide proper clubhead motion which determines the impact conditions. The literature review showed that most of the studies dealing with clubhead motion and effects of shaft flexibility are focused on drivers, as well as being based on numerical simulations. Our study included drivers, irons and pitching wedges, in order to obtain a better comparison of golfers' swing parameters. Another goal was to investigate the clubhead motion measured for highly skilled golfers, to complement and compare studies based on numerical modelling, as well as to overcome some inevitable assumptions used in the numerical simulation approach. The reviewed studies indicate that the clubhead path might be adequately fitted with a circular arc near the impact. Additionally, for improved representation of clubhead motion, the moving trihedron was introduced.

This experiment tests the hypothesis that kinematic parameters of club motion will not depend as much on the players' body type, motor patterns, but rather their individual golf swing characteristics.

\section{METHODS}

For the research, the clubhead and the ball motion was recorded with a high-speed imaging system. Three highly skilled (scratch) right-handed male golfers were chosen according to their body size (Table 1). The golfers used their own equipment and were asked to perform according to their best capabilities. The trials were performed on a golf course, where weather conditions were estimated as ideal, stable, with no wind.

After a warm-up routine, each golfer conducted three trials with a driver, two trials with an iron and two trials with a pitching wedge. The golfers were asked to make their own judgment regarding the quality of a particular trial. Only the trials which were judged as representative and successful by individual golfers were included in the analysis. 
Table 1 Player body data and trials

\begin{tabular}{|c|c|c|c|c|c|}
\hline \multirow[t]{2}{*}{ Player } & \multirow{2}{*}{$\begin{array}{l}\text { Body } \\
\text { height } \\
(\mathrm{cm})\end{array}$} & \multirow{2}{*}{$\begin{array}{c}\text { Body } \\
\text { mass } \\
(\mathrm{kg})\end{array}$} & \multicolumn{3}{|c|}{ Trials } \\
\hline & & & Driver & 6-iron & Pitching wedge \\
\hline 1 & 189 & 79.7 & $\begin{array}{l}(02) \\
(03)\end{array}$ & $\begin{array}{l}(10) \\
(11)\end{array}$ & $\begin{array}{l}(12) \\
(13)\end{array}$ \\
\hline 2 & 170 & 75.1 & $\begin{array}{l}(04) \\
(05) \\
(06)\end{array}$ & $\begin{array}{l}(14) \\
(15)\end{array}$ & $\begin{array}{l}(16) \\
(17)\end{array}$ \\
\hline 3 & 186 & 85.5 & $\begin{array}{l}(07) \\
(08) \\
(09)\end{array}$ & (18) & (20) \\
\hline
\end{tabular}

A post-analysis of the results revealed that three trials were not recorded properly due to triggering failure, or did not match the quality standards. One driver trial of Player 1 together with one 6-iron and one pitching wedge trial of Player 3 were omitted, while the successful ones were included in the analysis.

Kinematic analysis performed at the University of Ljubljana implies usage of different top quality motion capture systems and techniques described earlier by Čoh (2019) and Čoh, Tomažin, \& Štuhec (2006). In actual research, the high-speed imaging system consisted of two digital cameras at a frame rate of $2000 \mathrm{fps}$ and $512 \times 512$ pixel resolution. The camera's intrinsic and extrinsic parameters were estimated using a photogrammetric calibration technique, implemented in the Matlab (Natick, MA) Calibration Toolbox (Bouguet, 2013).

Three characteristic tracked points $\mathrm{T}_{1}, \mathrm{~T}_{2}, \mathrm{~T}_{3}$ were chosen on the clubhead, and an additional point $T_{B}$ was defined at the ball centre (Figure 1). The tracked point trajectories were digitized and transformed into the global frame $\mathrm{x}, \mathrm{y}, \mathrm{z}$ the origin $O$ of which was defined near the ball position with positive axis directions: $x$ - forward (target), $y$ - to the left, $z$ - upward. Smoothing spline was used to smooth the point trajectories, with the time parameter set to zero at the impact.
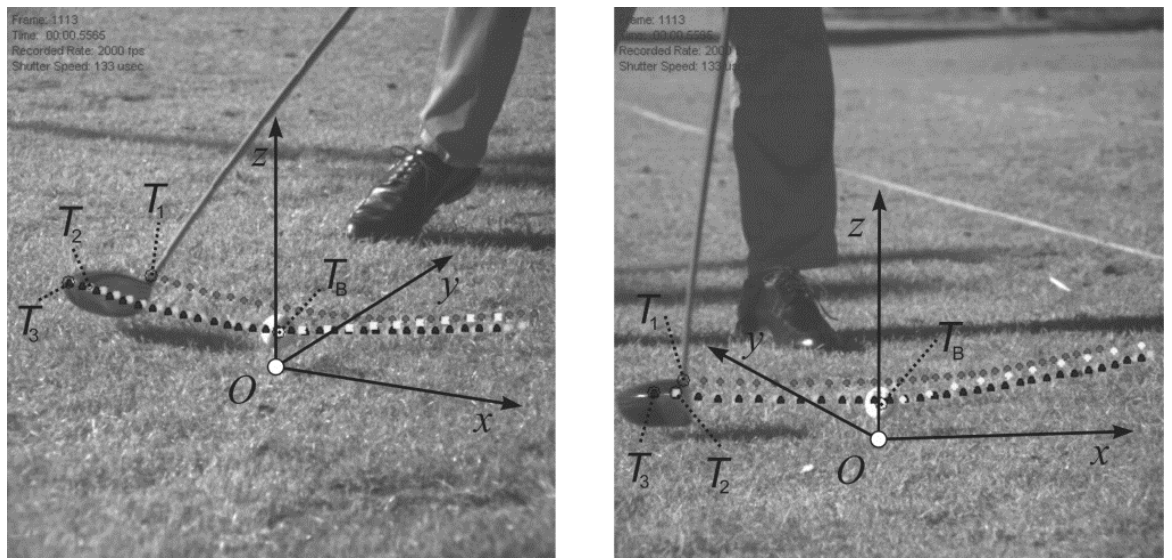

Fig. 1 Tracked points on the clubhead and the ball 
Each club was examined to obtain geometrical relations between the tracked points on the clubhead and face orientation. A local frame with the origin in the clubface centre to the clubhead was considered as a rigid body (Figure 2 ). Base vectors $\mathbf{f}, \mathbf{g}, \mathbf{h}$ define the orientation of the local axes $x^{\prime} y^{\prime} z$ ', where $\mathbf{g}$ is collinear with the hosel axis, $\mathbf{f}$ horizontal and perpendicular to $\mathbf{g}, \mathbf{h}$ perpendicular to both $\mathbf{f}$ and $\mathbf{g}$. Additional $u$ and $v$ axes were determined for locating the impact spot on the clubface.

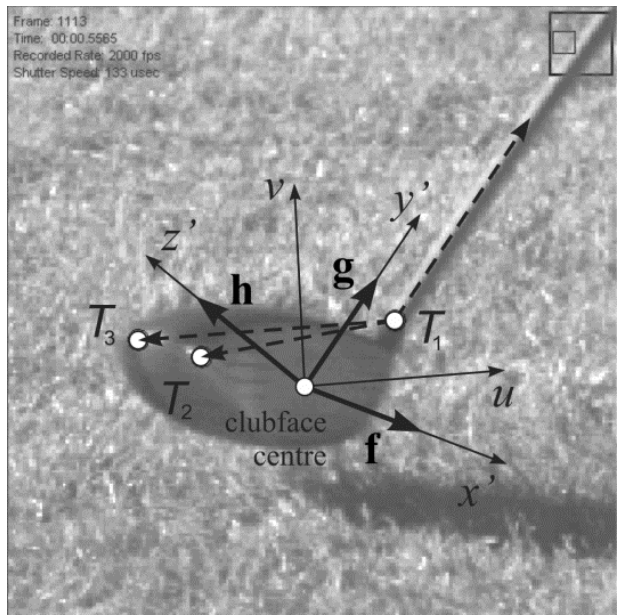

Fig. 2 Local frame of the clubhead fgh, local frame of the clubface $u v$

For the given local coordinates of points $\mathrm{T}_{1}, \mathrm{~T}_{2}, \mathrm{~T}_{3}$ on the clubhead, their global position was compared to their global positions obtained from the high-speed imaging system. The clubhead position and orientation were then estimated using least-square minimization and singular value decomposition, together with root mean square error for each frame recorded (Challis, 1995). For the motion analysis, a proprietary module was programmed in Matlab.

As stated by the studies referenced, the clubhead generally does not move in a single plane during a downswing, nor has a fixed centre of rotation. However, in our study we assumed that the clubhead motion can be regarded with high degree of accordance as circular in the proximity of the impact. The swing plane and the circle were fitted to the data using the Matlab Optimization Toolbox.

First, a built-in function for principal component analysis was used to find the normal vector and the position of the fitted swing plane. The origin $O$ ' of the clubhead local frame was selected as the reference point to fit the swing plane and the circle (Figure 2). Analysis of the clubhead motion observed on the cameras gave a sequence of $N$ positions over the length of $0.5 \mathrm{~m}$ in the $x$-direction, $P_{i}=O^{\prime}{ }_{i=1, \ldots N}$, each representing a data point for the fitting algorithm. 
Next, the data points were projected onto the fitted plane. The distance of the $i$-th data point with coordinates $\mathbf{r}^{P i}=\left[x_{i}, y_{i}, \mathbf{z}_{i}\right]^{T}$ was calculated:

$$
d_{i}=n_{p l, x}\left(x_{i}-x_{0}\right)+n_{p l, y}\left(y_{i}-y_{0}\right)+n_{p l, z}\left(z_{i}-z_{0}\right)=\mathbf{n}_{p l}\left(\mathbf{r}^{P_{i}}-\mathbf{r}_{0}\right)
$$

where $\mathbf{r}_{0}=\left[x_{0}, y_{0}, z_{0}\right]^{T}$ is an arbitrary point on the plane and $\mathbf{n}_{p l}=\left[n_{p l, x}, n_{p l, y}, n_{p l, z}\right]^{T}$ is the plane normal, resulting from the principal component analysis.

Thus, the position vector of the data point $P_{i}$, projected onto the fitted swing plane, is

$$
\mathbf{r}_{p r o j}^{P_{i}}=\mathbf{r}^{P_{i}}-d_{i} \mathbf{n}_{p l}
$$

A nonlinear optimization problem was defined, where the objective function,

$$
\min \sum_{i}\left(\left|\mathbf{r}_{\text {proj }}^{P_{i}}-\mathbf{r}^{C}\right|-r\right)^{2}
$$

was minimized over the radius $r$ of the fitted circle and the coordinates of its centre $C$, $\mathbf{r}^{C}=\left[x^{C}, y^{C}, z^{C}\right]^{T}$, located on the swing plane. The goodness of fit was estimated with the root mean square error.

For the points on the fitted circle, a moving trihedron with base vectors $\mathbf{t}, \mathbf{n}, \mathbf{b}$ was defined (Figure 3 ), where $\mathbf{t}$ is a tangent vector, $\mathbf{n}$ is a normal vector directed to the centre of the circle $C$ and $\mathbf{b}$ is a binormal vector with the same direction as the swing plane normal $\mathbf{n}_{p l}$. Vectors $\mathbf{t}$ and $\mathbf{n}$ lie in the swing plane. In case of pure circular motion of the clubhead, the local frame fgh does not change its orientation with respect to the moving trihedron tnb.

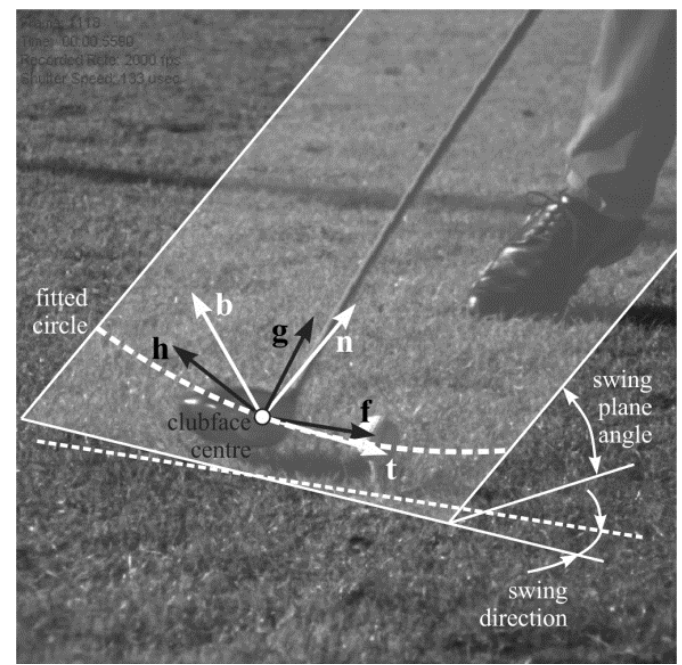

Fig. 3 Clubhead local frame fgh and fitted circle with moving trihedron tnb 

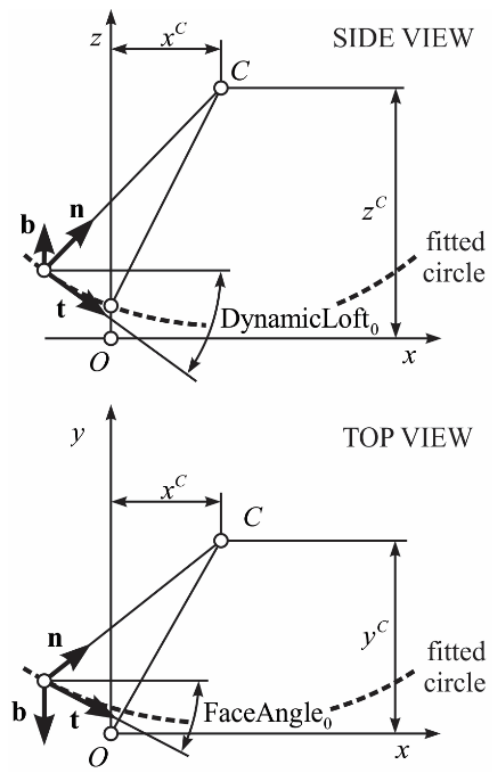

Fig. 4 Orientation of the tangent vector $t$ of the moving trihedron tnb

The following parameters were used to characterize the clubhead motion: swing plane angle and direction, fitted circle (centre and radius), clubhead speed for the clubface centre, the club path (CP), the angle of attack (AA) and orientation of the clubhead. The latter was used for determination of the face angle (FA), the dynamic loft (DL) and the spin loft (SL). For the drivers, it was considered that the clubface has a spherical shape (bulge, roll) with a typical $254 \mathrm{~mm}$ radius. The ball motion was characterized by the launch angle, direction and speed.

The ball contact force acts in the opposite direction of the clubhead motion, forcing the clubhead to lag. Additional clubhead rotation occurs at off-centre shots. The impact spot located towards the heel causes "out-to-in" rotation, decreasing the FA, while the toe impact causes the opposite. Due to the clubface curvature on drivers, hitting high on the clubface increases DL and launch angle; off-centre impacts also produce a vertical or horizontal gear effect (Carman \& Milburn, 2006).

The lead/lag deflection was estimated from the angles between $\mathrm{f}, \mathrm{t}$ projected on the swing plane tn in the direction of $b$, where counter-clockwise rotation was regarded as positive (lead deflection). The toe up/down deflection was estimated with the angle between $\mathrm{b}, \mathrm{h}$ projected on the moving plane $\mathrm{nb}$ in the direction of $\mathrm{t}$, with counterclockwise rotation having a positive sign (toe down deflection). Rotation around the shaft axis was estimated by the angle between $\mathrm{f}, \mathrm{t}$ projected on the plane bt in direction of $\mathrm{n}$, where counter-clockwise rotation is regarded as positive. The following curves were plotted after motion analysis: lead/lag deflection $\mathrm{f}-\mathrm{t} / \mathrm{b}$, toe up/down deflection $\mathrm{h}-\mathrm{b} / \mathrm{t}$ and longitudinal axis rotation $\mathrm{f}-\mathrm{t} / \mathrm{n}$. 
As the DL and the FA are measured in the global coordinates, they are not constant when the clubhead moves through the impact zone. For the purpose of easier representation of the clubhead motion, the tangent vector $t$ of the moving trihedron on the fitted circle was observed. From the tangent $t$ projected on the vertical plane xy and on the ground plane xy, the angles DynamicLoft0 (DL0) and FaceAngle0 (FA0) can be defined which show how direction of the tangent vector $t$ changes (Figure 4).

In case of pure circular motion, $\mathrm{DL}_{0}$ increases and $\mathrm{FA}_{0}$ closes. The clubhead local frame fgh (Figure 2) is based on the static loft and FA of each club, which generally differs from the moving trihedron tnb as established in post-analysis of the swing. DL and FA curves may appear shifted with respect to $\mathrm{DL}_{0}$ and $\mathrm{FA}_{0}$ curves even in case of circular motion of the clubhead (Figures 5 to 7). Any deviation from the pure circular motion in terms of the clubhead orientation is primarily reflected in the shape of the DL and FA curves.

\section{RESULTS}

The measured parameters of the clubhead and ball motion are presented in Tables 2 and 3. Time histories of the motion parameters are depicted in Figures 5 to 7.

In driver trials, the clubhead speed 48.00-50.17 m/s $\mathrm{s}^{-1}$ corresponded to the "GolferFast" of MacKenzie (2011). The AA for Players 2 and 3 was much higher than average on the PGA tour, $-1.3^{\circ}$ (Trackman, 2014). However, their results were comparable with the PGA average for the 6-iron, $-4.1^{\circ}$, and the pitching wedges, $-5.0^{\circ}$. The measured motion parameters are also consistent with the launch monitor data based on numerous players (Trackman, 2009), which showed that the launch direction depends by approximately $85 \%$ on the FA when using drivers (75\% when using irons), and the rest on the $\mathrm{CP}$; a similar relation exists also for the launch angle, with the DL being the dominant parameter over the AA.

In iron trials, the clubhead speed, $37.99-40.83 \mathrm{~m} \cdot \mathrm{s}^{-1}$, and the ball speed, 52.44$55.10 \mathrm{~m} \cdot \mathrm{s}^{-1}$ (Tables 4 and 5), corresponded to "the high ball speed" group of Healy, et al. (2011). The swing plane angle was $45.2-52.5^{\circ}$, which for Player 2 was smaller than in his driver trials (05) and (06). The AA was between $-1.1^{\circ}$ and $-4.0^{\circ}$, which is lower than observed previously (McCloy, Wallace, \& Otto, 2006).

In pitching wedge trials the clubhead speed was in a narrow range $35.99-36.49 \mathrm{~m} \cdot \mathrm{s}^{-1}$, while the ball speed varied between $42.12 \mathrm{~m} \cdot \mathrm{s}^{-1}$ (12) and $46.01 \mathrm{~m} \cdot \mathrm{s}^{-1}$ (20). Compared to the drivers (Figure 5) and the irons (Figure 6), the clubhead motion parameters for the pitching wedge trials (Figure 7) do not change as abruptly at impact. This observation is in accordance with a shorter, stiffer shaft and lower speed at impact, which generates smaller contact force. It is also expected that shaft deflection in the swing plane is lower due to a smaller component of the contact force, pointing opposite to the motion. 
Table 2 Parameters of clubhead motion

\begin{tabular}{|c|c|c|c|c|c|c|c|c|c|c|}
\hline Player & Trial & $\begin{array}{c}\text { Swing plane } \\
\left({ }^{\circ}\right)\end{array}$ & $\begin{array}{c}\text { Swing direct. } \\
\left({ }^{\circ}\right)\end{array}$ & $\begin{array}{l}\text { CP } \\
\left(^{\circ}\right)\end{array}$ & $\begin{array}{l}\text { FA } \\
\left({ }^{\circ}\right)\end{array}$ & $\begin{array}{c}\text { AA } \\
\left({ }^{\circ}\right)\end{array}$ & $\begin{array}{l}\text { DL } \\
\left({ }^{\circ}\right)\end{array}$ & $\begin{array}{c}\text { SL* } \\
\left({ }^{\circ}\right)\end{array}$ & $\begin{array}{l}\text { Speed } \\
\left(\mathrm{m}^{-1} \mathrm{~s}^{-1}\right)\end{array}$ & $\begin{array}{l}\text { RMSE } \\
(\mathrm{m})\end{array}$ \\
\hline \multicolumn{11}{|l|}{ Driver } \\
\hline \multirow[t]{2}{*}{1} & (02) & 36.8 & -3.2 & -4.2 & -.5 & .8 & 13.6 & 12.9 & 50.00 & .00170 \\
\hline & (03) & 36.6 & -.3 & -2.7 & .2 & 1.7 & 14.9 & 13.2 & 50.23 & .00153 \\
\hline \multirow[t]{3}{*}{2} & (04) & 52.1 & 5.4 & .9 & -4.6 & 5.8 & 11.7 & 5.9 & 49.54 & .00096 \\
\hline & (05) & 60.4 & 3.9 & .0 & -7.1 & 6.8 & 11.4 & 4.6 & 48.59 & .00189 \\
\hline & (06) & 57.7 & 4.7 & .6 & -6.0 & 6.6 & 12.3 & 5.7 & 48.00 & .00155 \\
\hline \multirow[t]{3}{*}{3} & (07) & 50.1 & 9.0 & 2.8 & -.4 & 7.4 & 10.8 & 3.4 & 49.43 & .00190 \\
\hline & (08) & 43.4 & 7.9 & 1.2 & .6 & 6.3 & 12.5 & 6.2 & 50.17 & .00181 \\
\hline & (09) & 43.3 & 10.4 & 2.9 & 1.7 & 7.1 & 10.9 & 3.8 & 49.81 & .00189 \\
\hline \multicolumn{11}{|l|}{ Iron } \\
\hline \multirow[t]{2}{*}{1} & (10) & 45.2 & -7.5 & -3.6 & -1.1 & -4.0 & 24.9 & 28.8 & 40.54 & .00076 \\
\hline & (11) & 50.4 & -1.0 & 2.2 & .3 & -3.8 & 21.9 & 25.7 & 39.49 & .00196 \\
\hline \multirow[t]{2}{*}{2} & (14) & 51.6 & -0.5 & .3 & -1.2 & -1.1 & 22.0 & 23.0 & 37.99 & .00079 \\
\hline & (15) & 52.5 & .6 & 1.8 & 2.7 & -1.5 & 25.1 & 26.6 & 39.64 & .00086 \\
\hline 3 & (18) & 47.4 & 1.7 & 5.1 & 5.6 & -3.8 & 21.2 & 25.0 & 40.83 & .00131 \\
\hline \multicolumn{11}{|l|}{ Wedge } \\
\hline \multirow[t]{2}{*}{1} & (12) & 46.3 & -6.8 & -1.9 & -6.9 & -5.1 & 37.8 & 42.9 & 35.99 & .00099 \\
\hline & (13) & 59.5 & -1.7 & .9 & -.3 & -4.4 & 41.2 & 45.6 & 35.80 & .00139 \\
\hline \multirow[t]{2}{*}{2} & (16) & 55.3 & -2.4 & -.1 & -.8 & -3.4 & 38.4 & 41.8 & 36.13 & .00171 \\
\hline & (17) & 55.7 & -.8 & 2.0 & .8 & -4.0 & 35.8 & 39.9 & 36.73 & .00109 \\
\hline 3 & (20) & 55.2 & 5.3 & 9.0 & 5.0 & -5.5 & 31.8 & 37.3 & 36.49 & .00138 \\
\hline
\end{tabular}

Table 3 Fitted circle and ball motion parameters

\begin{tabular}{|c|c|c|c|c|c|c|c|c|c|c|c|}
\hline \multirow[t]{2}{*}{ Player } & \multirow[t]{2}{*}{ Trial } & \multicolumn{5}{|c|}{ Fitted circle } & \multicolumn{2}{|c|}{$\begin{array}{c}\text { Impact spot } \\
\text { location }\end{array}$} & \multicolumn{3}{|c|}{ Ball } \\
\hline & & $\begin{array}{l}x^{c} \\
(\mathrm{~m})\end{array}$ & $\begin{array}{l}y^{C} \\
(\mathrm{~m})\end{array}$ & $\begin{array}{l}z^{C} \\
(\mathrm{~m})\end{array}$ & $\begin{array}{l}r^{c} \\
(\mathrm{~m})\end{array}$ & $\begin{array}{c}\text { RMSE } \\
(\mathrm{m})\end{array}$ & $\begin{array}{c}u^{*} \\
(\mathrm{~cm})\end{array}$ & $\begin{array}{l}v^{* *} \\
(\mathrm{~cm})\end{array}$ & $\begin{array}{l}\text { Speed } \\
\left(\mathrm{m} \cdot \mathrm{s}^{-1}\right)\end{array}$ & $\begin{array}{c}\text { Launch angle } \\
\left({ }^{\circ}\right)\end{array}$ & $\begin{array}{c}\text { Launch direct. } \\
\left({ }^{\circ}\right)\end{array}$ \\
\hline \multicolumn{12}{|l|}{ Driver } \\
\hline \multirow[t]{2}{*}{1} & (02) & .020 & .922 & .722 & 1.158 & .00082 & 0.6 & -.5 & 72.35 & 11.9 & -1.2 \\
\hline & (03) & .032 & .862 & .667 & 1.080 & .00090 & 0.6 & -.2 & 72.87 & 11.9 & .0 \\
\hline \multirow[t]{3}{*}{2} & (04) & -.027 & .635 & .831 & 1.014 & .00097 & -0.4 & -.2 & 71.01 & 10.2 & -3.9 \\
\hline & (05) & -.068 & .523 & .954 & 1.062 & .00094 & 1.4 & -.4 & 68.72 & 10.8 & -5.7 \\
\hline & (06) & -.064 & .553 & .904 & 1.032 & .00092 & 1.2 & -.6 & 68.12 & 11.2 & -5.1 \\
\hline \multirow[t]{3}{*}{3} & (07) & -.016 & .704 & .872 & 1.089 & .00073 & 1.3 & -1.4 & 70.81 & 10.3 & .2 \\
\hline & (08) & -.002 & .785 & .781 & 1.079 & .00121 & 1.1 & -.9 & 71.61 & 11.5 & .7 \\
\hline & (09) & .022 & .800 & .796 & 1.102 & .00091 & 1.5 & -1.2 & 70.29 & 10.5 & 2.0 \\
\hline \multicolumn{12}{|l|}{ Iron } \\
\hline \multirow[t]{2}{*}{1} & (10) & .087 & .715 & .698 & 1.013 & .00093 & -1.8 & -.7 & 54.80 & 17.4 & -1.6 \\
\hline & (11) & .150 & .640 & .751 & .981 & .00079 & -2.9 & -.8 & 54.51 & 15.6 & 0.6 \\
\hline \multirow[t]{2}{*}{2} & (14) & .087 & .616 & .777 & .997 & .00082 & -.4 & -.3 & 53.93 & 17.6 & -0.8 \\
\hline & (15) & .110 & .604 & .793 & 1.005 & .00065 & -.1 & -.7 & 52.44 & 17.6 & 2.5 \\
\hline 3 & (18) & .190 & .677 & .721 & 1.016 & .00105 & -1.1 & 1.5 & 55.10 & 15.8 & 5.6 \\
\hline \multicolumn{12}{|l|}{ Wedge } \\
\hline \multirow[t]{2}{*}{1} & (12) & .123 & .697 & .719 & .993 & .00096 & -1.9 & -2.3 & 42.18 & 26.3 & -5.4 \\
\hline & (13) & .132 & .478 & .789 & .927 & .00121 & -1.9 & -1.5 & 42.49 & 31.6 & .0 \\
\hline \multirow[t]{2}{*}{2} & (16) & .107 & .578 & .843 & 1.031 & .00122 & .1 & -1.3 & 43.42 & 27.3 & -.6 \\
\hline & (17) & .125 & .551 & .826 & 1.005 & .00095 & .2 & -1.2 & 43.34 & 27.0 & 1.1 \\
\hline 3 & (20) & .239 & .548 & .802 & 1.009 & .00010 & -1.3 & .8 & 46.01 & 23.8 & 6.1 \\
\hline
\end{tabular}



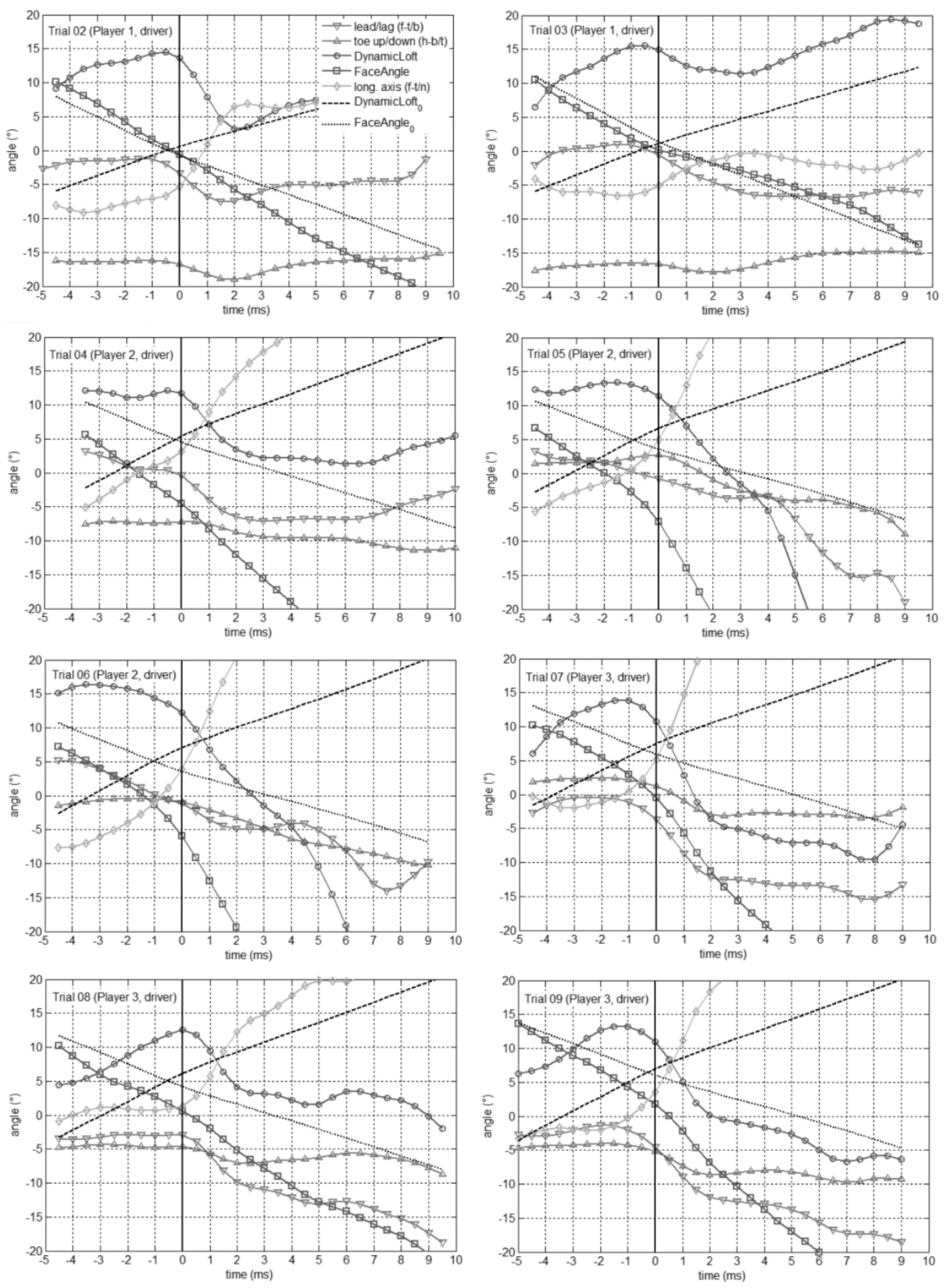

Fig. 5 Parameters of clubhead motion in driver trials 

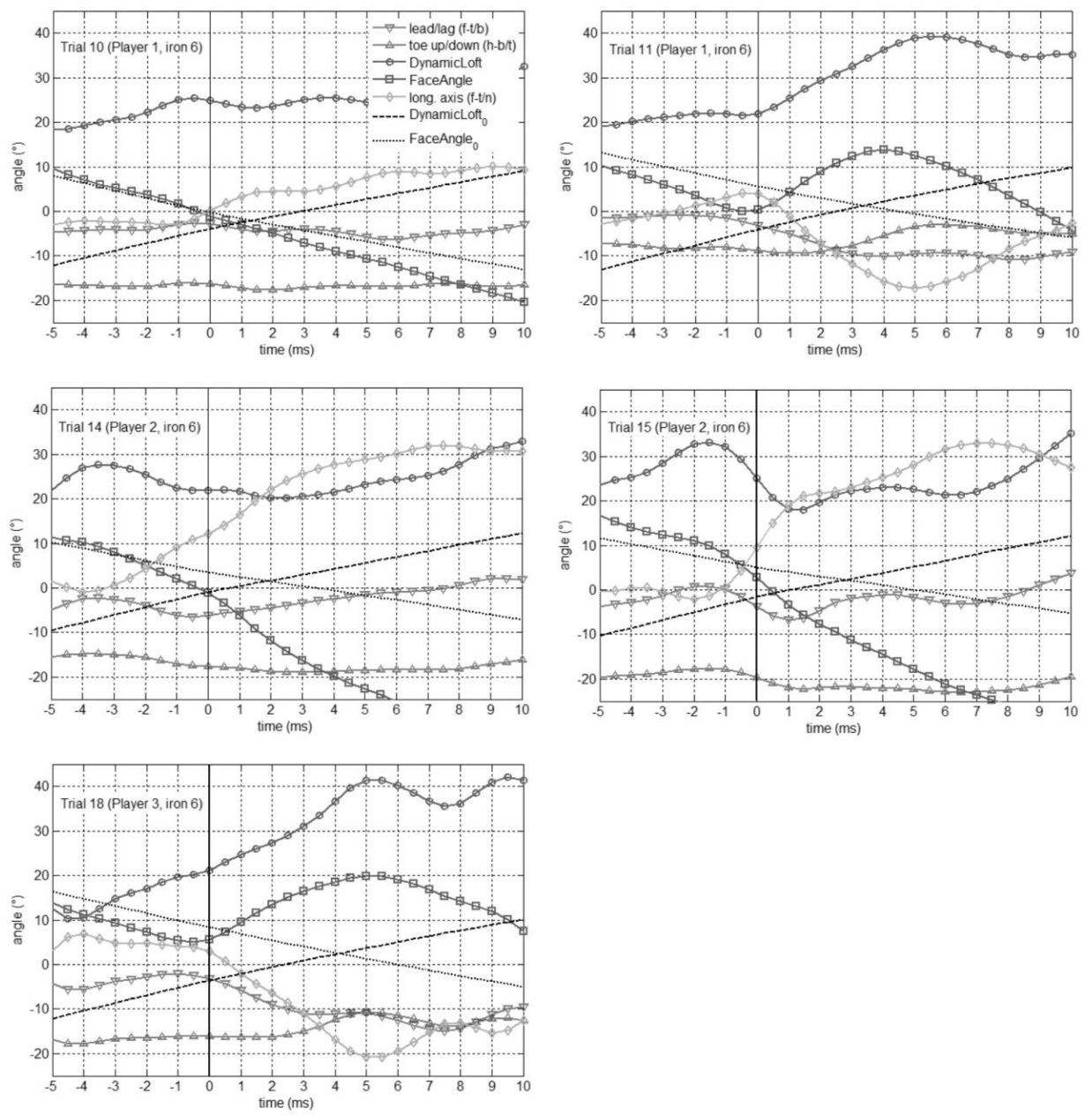

Fig. 6 Parameters of clubhead motion in iron trials 

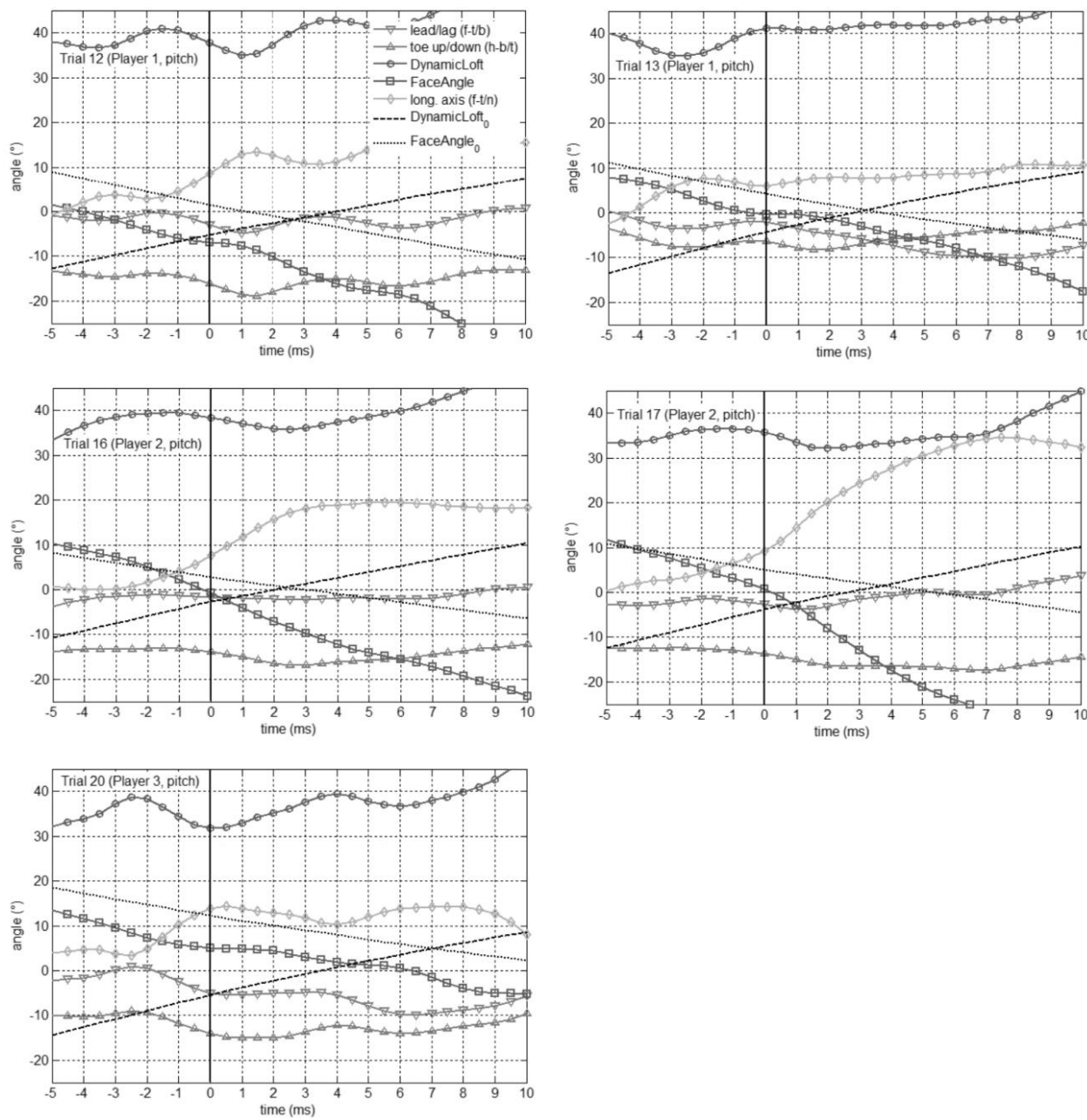

Fig. 7 Parameters of clubhead motion in pitching wedge trials

\section{DISCUSSION}

With the introduction of the moving trihedron on the fitted circle, a reference frame was defined for observing the changes in orientation of the clubhead during the swing. The results of our study support a circular arc as suitable for modelling the clubhead path near the impact. Any shaft deflection results in rotation of the clubhead local frame relative to the moving trihedron.

Player $1(189.2 \mathrm{~cm}, 79.7 \mathrm{~kg})$ had the shallowest swing plane, $36.6^{\circ}-36.8^{\circ}$, compared to Player $3(186.2 \mathrm{~cm}, 85.5 \mathrm{~kg})$, and Player $2(170.2 \mathrm{~cm}, 75.1 \mathrm{~kg})$, who had the steepest plane of $52.1^{\circ}-60.4^{\circ}$, despite the lowest body height. The radius $r^{C}$ ranged from $1.014 \mathrm{~m}$ (Player $2,04)$ to $1.158 \mathrm{~m}$ (Player 1, 02). However, $r^{C}$ was in a narrow range, $.981-1.016 \mathrm{~m}$ for the 
irons and .993-1.039 $\mathrm{m}$ for the pitching wedges, with the exception of $0.927 \mathrm{~m}$ (Player 1, 13). These results suggest that body height is not decisive regarding the radius of the fitted circle as expected due to distinctively different body types of the players, able to achieve comparable speed. Previous research showed the swing plane of the clubhead flattens in the last $20 \%$ of the downswing, presumably due to ulnar deviation and left arm supination (Coleman \& Anderson, 2007; Coleman \& Rankin, 2005), while the steepest plane, $66.4^{\circ}$, was established for pitching wedges, $62.9^{\circ}$ for 5 -irons and the flattest for drivers, $54.5^{\circ}$. Our study confirmed those findings for Players 1 and 3, but not for Player 2.

The swing plane also locates the fitted circle with respect to the ball. Player $1(03)$ had a loosely closed swing plane direction, $-0.3^{\circ}$, while Player $3(08)$ had a distinctively open one, $7.9^{\circ}$, with only minor differences in $x^{C}$ and $r^{C}$. Thus, the lowest point of the fitted circle in (08) is positioned more backwards from the ball, which enables Player 3 to generate large AA. Player 1, despite the low AA, 0.8-1.7 ${ }^{\circ}$, still achieved rather high DL, 13.6-14.9 . Player 2 showed an open swing direction, 3.9-5.4 $4^{\circ}$, with $x^{C}$ between -.027 and $-.068 \mathrm{~m}$, positioning the fitted circle backwards and enabling large AA, 5.8-6.8 ${ }^{\circ}$, together with squared CP.

Player 1 conducted nearly centre impacts, the ball speed was $72.35 \mathrm{~m} \cdot \mathrm{s}^{-1}$ (02) and $72.87 \mathrm{~m} \cdot \mathrm{s}^{-1}(03)$, but at a fairly large SL, $12.9^{\circ}$ and $13.2^{\circ}$. The DL (Figure 5) decreases after the impact, together with the lead deflection decrease and rotation around the shaft axis. FA closes almost linearly; the rate of closing was slightly decreased in trial (03). Player 3 achieved the highest ball speed in (08), $71.61 \mathrm{~m} \cdot \mathrm{s}^{-1}$, and slightly less in (07) and (09), where the SL, $3.4^{\circ}$ and $3.8^{\circ}$, was considerably lower compared to $6.2^{\circ}(08)$. Low SL, 4.6-5.9 ${ }^{\circ}$, could also be observed in trials (04) to (06) of Player 2. Possible reasons for the low SL are the capability of Player 3 to achieve high AA (6.3-7.4 $)$ and low DL, $10.8^{\circ}(07)$ and $10.9^{\circ}$ (09). In (08), the DL reaches the maximum value at impact, and is parallel to the $\mathrm{DL}_{0}$ curve (Figure 4); pre-impact lead/lag deflection, toe up/down deflection and shaft axis rotation remain nearly constant, indicating the clubhead motion is close to circular. In trials (07) and (09), DL decreases during the impact, after the maximum value of approximately $1.0 \mathrm{~ms}$ occurs before the impact. Furthermore, there is a lead/lag deflection decrease and the rotation around the shaft axis. This is in accordance with the typical pattern of shaft deflection, where lead deflection contributes to DL and closing the clubface (MacKenzie \& Sprigings, 2009a). Player 2 showed a distinctive swing style, with closed FA in driver trials. The rotation around the shaft longitudinal axis before the impact indicates supination of the left forearm (Figure 5). A possible explanation is that Player 2 positioned the clubhead under the swing plane, which due to the ulnar deviation in the downswing contributes to a rapid decrease of a combined moment of inertia (forearm, hand and club) and may add over $20 \%$ to the clubhead speed at the impact (MacKenzie, 2012).

Player 1 showed a distinctively closed swing direction also in the iron trials. With the fitted circle positioned at $x^{C}=.087 \mathrm{~m}$, a low AA, $-4.0^{\circ}$, resulted in trial (10), while trial (14) of Player 2 with a nearly squared swing direction and $\mathrm{CP}$ resulted in a larger $\mathrm{AA},-1.1^{\circ}$. In trial (18) of Player 3, the swing plane was slightly open, $1.7^{\circ}$; the fitted circle was positioned forwards, $x^{C}=.190 \mathrm{~m}$, resulting in the open $\mathrm{CP}, 5.1^{\circ}$, and lower AA, $-3.8^{\circ}$. The in-to-out swing was also observed with drivers (07)-(09) of Player 3. Comparison of the measured clubhead motion parameters with $\mathrm{DL}_{0}$ and $\mathrm{FA}_{0}$ curves in Figure 6 indicates that in trials (10), (11) and (18) the pre-impact motion was close to circular. Irons are typically stiffer than drivers, therefore smaller deflection can be expected.

In trials (11) and (18), longitudinal axis curve decreases after impact, while the clubface 
opens and DL increases. With the impact spot at the toe region in (11) and (18), a larger distance to the shaft axis increases the twisting torque from the ball contact force, causing rotation around the shaft axis in the opposite direction of the left arm supination. Compared to trial (10) of Player 1, the toe down deflection was lower in (11), positioning the impact spot further from the axis of rotation, thus increasing the twisting torque.

Trials (14) and (15) of Player 2 show more pre-impact dynamics. In (14), rotation around the shaft axis occurs during the impact, starting $4 \mathrm{~ms}$ earlier. DL and lead/lag deflection reach the maximum value of $3.5 \mathrm{~ms}$ before the impact, while FA closes with a higher rate than in a circular motion. In (15), DL and lead/lag deflection peak $1.5 \mathrm{~ms}$ before the impact. In the period $\pm 2 \mathrm{~ms}$ from the impact, $25^{\circ}$ rotation around the shaft axis occurs and continues at a lower rate. Player 2 exhibited rotation around the shaft axis during the impact also in his driver trials (04) to (06) (Figure 5).

For the pitching wedges, the lead/lag and toe up/down curves show a small shaft deflection in trials (16) and (17) of Player 2. Player 2 starts rotation around the shaft axis before the impact and continues through the impact, which can also be observed in his driver and iron trials. Player 1 hits low in the toe region in trials (12) and (13). In (12), DL decreases approx. $5^{\circ}$ between the peaks at $1.5 \mathrm{~ms}$ before and $4 \mathrm{~ms}$ after the impact. In (13), there is a $6^{\circ}$ decrease of the DL, already starting $6 \mathrm{~ms}$ before the impact. In trial (20) of Player 3, the DL changes $7^{\circ}$ between the two peaks $6.5 \mathrm{~ms}$ apart. Simultaneous changes can be observed for lead/lag deflection, toe up/down deflection and longitudinal axis rotation. Player 1 exhibited large variation of the swing plane angle, $46.3^{\circ}-59.5^{\circ}$, and a distinctively out-to-in swing, resulting in a launch direction $-5.4^{\circ}$ in trial (12). Player 3 (20) showed in-to-out swing with the fitted circle positioned forward, $x^{C}=.239 \mathrm{~m}$, giving the launch direction of $6.1^{\circ}$.

Diagrams on Figures 5 to 7 show mutual dependency of the clubhead motion parameters, particularly of DL vs. lead/lag deflection and shaft axis rotation. This behaviour partially results from representation of the clubhead orientation, where the DL and FA are referenced with respect to the ground, while shaft deflection and shaft axis rotation are referenced with respect to the moving trihedron. DL and FA both reflect the clubhead rotation around horizontal or vertical axis, perpendicular to the target line and lying close to the moving plane nb. The rotations around the horizontal or the vertical axis can be observed, if the angle between $\mathbf{f}$ and $\mathbf{t}$ is projected in direction of $\mathbf{b}$ or $\mathbf{n}$, on the lead/lag curve $\mathbf{f}-\mathbf{t} / \mathbf{b}$ and the shaft axis rotation curve $\mathbf{f}-\mathbf{t} / \mathbf{n}$. The rotations around the horizontal or the vertical axis can be noticed to a much lesser extent, when the angle between $\mathbf{h}$ and $\mathbf{b}$ is projected in direction of $\mathbf{t}$, on the toe up/down curve h-b/t. Vice versa, both lead/lag deflection and shaft axis rotation are reflected in DL and FA. Lead deflection results in an increased DL and closed clubface simultaneously (MacKenzie \& Sprigings, 2009c). Also, supination of the left arm contributes to the club rotation around the shaft axis. Previous studies estimated torsional deformation to be as small as $.2^{\circ}-.5^{\circ}$ for steel shafts with only a minor effect on the clubhead speed and orientation (MacKenzie \& Sprigings, 2009c; Penner, 2003), while not exceeding $1.0^{\circ}$ at impact (Betzler, 2010). Changes of the projected angles $\mathbf{f}-\mathbf{t} / \mathbf{b}$ and $\mathbf{f}-\mathbf{t} / \mathbf{n}$ observed in Figure 5 exceed the expected shaft twist by far.

Considering the diagrams in Figures 5 to 7, the DL appears to be a more responsive quantity than the FA, which changes almost linearly up to the impact. After the impact, the clubface tends to open when the ball contacts the clubface in the toe region. The DL tends to decrease after the impact at the centre or low on the clubface, which is in accordance with other results based on the video monitoring system (Ellis, Roberts, \& Sanghera, 2010). 
Swing parameters can show significant changes shortly before the impact, implicating inconsistency to impact conditions, which can be difficult to control. In driver trials of Players 1 and 2, particularly in (08), one can observe only small changes of the moving trihedron orientation, indicating almost a circular motion of the clubhead. Both players were able to achieve a higher clubhead and ball speed, but more trials are needed to establish how achieving circular motion can contribute to consistent impact conditions.

A limited number of players and trials were used in the study, enabling only a comparative analysis of the clubhead motion parameters. As high skilled golfers exhibit significantly more consistent trials (Betzler, Monk, Wallace, \& Otto, 2012), it was still possible to reveal main characteristics of the individual player technique. However, for indepth analysis the study should be performed on a larger sample, with the whole body dynamics included.

\section{CONCLUSION}

Our study showed that fitting the clubhead path with a circular arc is adequate on a narrow range around the impact. For the players included in the study, differences were small for the fitted arc radius as well for the clubhead speed at impact. This fact indicates that the players achieved comparable angular velocity of the clubhead, regardless of their body size. The differences in club motion parameters can be attributed to the players' body type, motor patterns and their signature golf swing. A comparison of the trials analysed also showed that players exhibit similar swing characteristics for all the clubs used. The fitted circular arc and the moving trihedron proved to be a useful approach for representation of the clubhead motion. It offers additional insight into club motion and the evaluation of the player's performance and possible errors, which results in impact conditions.

\section{REFERENCES}

Bouguet, J.Y. Camera calibration toolbox for Matlab. Retrieved March 29, 2013 from the World Wide Web: http://www.vision.caltech.edu/bouguetj/calib_doc/

Betzler, N., Monk, S., \& Wallace, E. (2008). From the double pendulum model to full-body simulation: evolution of golf swing modeling. Sports Technology Review, 1(4-5), 175-188.

Betzler, N.F. (2010). The effect of differing shaft dynamics on the biomechanics of the golf swing. PhD Thesis, Edinburgh Napier University, UK

Betzler, N.F., Monk, S.A., \& Wallace, E.S. (2012). Effects of golf shaft stiffness on strain, clubhead presentation and wrist kinematics. Sports Biomechanics, 11(2), 223-238.

Betzler, N.F., Monk, S.A., Wallace, E.S., \& Otto, S.R. (2012). Variability in clubhead representation characteristics and ball impact location for golfers' drives. Journal of Sports Sciences, 30(5), 439-448.

Carman, A.B., \& Milburn, P.D. (2006). Determining rigid body transformation parameters from ill-conditioned spatial marker co-ordinates. Journal of Biomechanics, 1778-1786.

Challis, J.H. (1995). A procedure for determining rigid body transformation. Journal of Biomechanics, 28(6), 733-737.

Čoh, M. (2019). Usain Bold-Biomechanical model of sprint technique. Facta Universitatis Series Physical Education and Sport, 17(1), 1-13.

Čoh, M., Tomažin, K., \& Štuhec, S. (2006). The biomechanical model of the sprint start and block acceleration. Facta Universitatis Series Physical Education and Sport, 4(2), 103-114.

Coleman, S., \& Rankin, A.J. (2005). A three-dimensional examination of the planar nature of the golf swing. Journal of Sports Sciences, 23(3), 227-234.

Coleman, S., \& Anderson, D. (2007). An examination of the planar nature of golf club motion in the swings of experienced players. Journal of Sports Sciences, 25(7), 739-748. 
Egret, C., Vincent, O., \& Weber, J. (2003). Analysis of 3D Kinematics concerning three different clubs in golf swing. International Journal of Sports Medicine, 24, 465-469.

Ellis, K.L., Roberts, J.R., \& Sanghera, J. (2010). Development of a method for monitoring clubhead path and orientation through impact. In: A. Sabo, P. Kafka, S. Litzenberger \& C. Sabo (Eds.), Procedia Engineering 2, $8^{\text {th }}$ Conference of the International Sports Engineering Association-ISEA, (pp. 2955-2960). Vienna: Elsevier.

Healy, A., Moran, K.A., \& Dickson, J. (2011). Analysis of the 5 iron golf swing when hitting for maximum distance. Journal of Sports Sciences, 29(10), 1079-1088.

Kenny, I.C., McCloy, A.J., \& Wallace, E.S. (2008). Segmental sequencing of kinetic energy in a computersimulated golf swing. Sports Engineering, 11,37-45.

Kenny, I.C., Wallace, E.S., \& Otto, S.R. (2008). Driving performance variability among elite golfers. In: M. Estivalet \& P. Brisson (Eds.), The Engineering of Sport 7, Vol. 1, (pp. 387-395). Paris: Springer-Verlag.

MacKenzie, S.J., \& Sprigings, E.J. (2009a). Understanding the role of shaft stiffness in the golf swing. Sports Engineering, 12(1), 13-19.

MacKenzie, S.J., \& Sprigings, E.J. (2009b). Understanding the mechanisms of shaft deflection in the golf swing. Sports Engineering, 12(2), 69-75.

MacKenzie, S.J., \& Sprigings, E.J. (2009c). A three-dimensional forward dynamics model of the golf swing. Sports Engineering, 11(4), 165-175.

MacKenzie, S.J. (2011). How does shaft flexibility affect the delivery of the clubhead to the ball? The Journal of Applied Golf Research, 3, 246-277.

MacKenzie, S.J. (2012). Club position relative to the golfer's swing plane meaningfully affects swing dynamics. Sports Biomechanics, 11(2), 149-164.

McCloy, A.J., Wallace, E.S., \& Otto, S.R. (2006). Iron golf club striking characteristics for male elite golfers. In: E.F. Moritz, \& S. Haake (Eds.), The Engineering of Sport 6, Vol. 2, (pp. 353-358). New York: Springer-Verlag.

McGinnis, R.S., \& Nesbit, S. (2010). Golf club deflection characteristics as a function of the swing hub path. The Open Sports Sciences Journal, 3, 155-164.

Nesbit, S.M. (2005). Three dimensional kinematic and kinetic study of the golf swing. Journal of Sports and Medicine, 5(4), 499-519.

Nesbit, S.M., \& McGinnis, R. (2009). Kinematic analyses of the golf swing hub path and its role in golfer/club kinetic transfers. Journal of Sports Science and Medicine, 8, 235-246.

Penner, A.R. (2003). The physics of Golf. Reports on progress in Physics, 66, 131-171.

Sandhu, S., Millard, M., \& McPhee, J. (2010). 3D dynamic modeling and simulation of a golf drive. Procedia Engineering, 2, 3243-3248.

Trackman Newsletter No. 4 (2009). Retrieved February 8, 2012 from: https://mytrackman.com/media/f4748268efb1-4d15-aa68-056b9273b687/5JFLWA/PDF/3.\%20Newsletter/newsletter4.pdf

Trackman. (June 6, 2014). TrackMan average tour stats. Retrieved October 16, 2015 from: http://blog.trackmangolf.com/trackman-average-tour-stats/

Vaughan, C.L. (1981). A three-dimensional analysis of the forces and torques applied by a golfer during the downswing. In: A. Morecki, K. Fidelius, K. Kedzior, \& A. Wit (Eds.), Biomechanics VII-B, (pp. 325-331). Warsaw: University Park Press.

\section{UPOREDNA ANALIZA KRETANJA GOLF PALICE PRILIKOM SUDARA SA LOPTICOM}

Svrha studije bila je da se istraži kinematika glave štapa u toku udarne faze zamaha u golfu. Tri profesionalna golfera različite morfologije izvršilo je udarce po loptici "driver", "6-iron" $i$ "pitching wedge" tehnikom. Sistem za snimanje pokreta velike brzine korišćen je za praćenje kretanja glave štapa neposredno pred udarac. Konvencionalni parametri zamaha u golfu korišćeni su za uporednu analizu. Pored toga, kružni luk je postavljen na trajektoriju glave štapa, a pokretni trojedar je uveden kao referentni okvir za posmatranje rotacije glave štapa. Uprkos razlikama u morfologiji, golferi su postigli približno istu brzinu glave palice, dok je radijus kružnog luka bio u uskom rasponu. Pomični trojedar, zajedno sa konvencionalnim parametrima golf zamaha omogućio je dodatni uvid u kretanje glave štapa i orijentaciju štapa u prostoru. Jasno su uočljive pojedinačne karakteristike zamaha, što omogućuje poboljšanje tehnike zamaha golfera.

Ključne reči: zamah u golfu, eksperiment, analiza kretanja, biomehanika, pokretni trojedar 